University of Wollongong

Research Online

Australian Institute for Innovative Materials -

Papers

Australian Institute for Innovative Materials

$1-1-2014$

Porous Ni0.5Zn0.5Fe204 nanospheres: synthesis, characterization, and application for lithium storage

\author{
Min Zhang \\ Chinese Academy of Sciences \\ Xuanwen Gao \\ University of Wollongong,xg973@uowmail.edu.au \\ Zhenfa Zi \\ Chinese Academy of Sciences \\ Jianming Dai \\ Chinese Academy of Sciences \\ Jiazhao Wang \\ University of Wollongong, jiazhao@uow.edu.au
}

See next page for additional authors

Follow this and additional works at: https://ro.uow.edu.au/aiimpapers

Part of the Engineering Commons, and the Physical Sciences and Mathematics Commons

Research Online is the open access institutional repository for the University of Wollongong. For further information contact the UOW Library: research-pubs@uow.edu.au 


\title{
Porous Ni0.5Zn0.5Fe204 nanospheres: synthesis, characterization, and application for lithium storage
}

\author{
Abstract \\ Monodisperse porous Ni0.5Zn0.5Fe204 nanospheres have been successfully synthesized by the \\ solvothermal method. The diameter of the nanospheres can be tuned by controlling the reactant \\ concentration. Lower reactant concentration is favoured for the synthesis of mesoporous

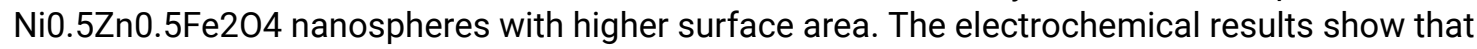 \\ mesoporous Ni0.5Zn0.5Fe2O4 nanospheres exhibit high reversible specific capacity (1110 mAh g-1) for \\ Li storage and high capacity retention, with $700 \mathrm{mAh}$ g-1 retained up to 50 cycles. The excellent \\ electrochemical properties could be attributed to the large surface area and mesoporous structure. The \\ results suggest that $\mathrm{Ni} 0.5 \mathrm{Zn} 0.5 \mathrm{Fe} 2 \mathrm{O} 4$ could be a promising high capacity anode material for lithium ion \\ batteries.

\section{Keywords} \\ lithium, application, characterization, synthesis, storage, nanospheres, porous, $5 \mathrm{fe} 2 \mathrm{o} 4,5 \mathrm{zn} 0$, ni0 \\ Disciplines \\ Engineering | Physical Sciences and Mathematics

\section{Publication Details} \\ Zhang, M., Gao, X., Zi, Z., Dai, J., Wang, J., Chou, S., Liang, C., Zhu, X., Sun, Y. \& Liu, H. (2014). Porous

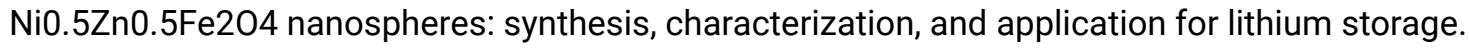 \\ Electrochimica Acta, 147 143-150.

\section{Authors} \\ Min Zhang, Xuanwen Gao, Zhenfa Zi, Jianming Dai, Jiazhao Wang, Shulei Chou, Changhao Liang, Xuebin \\ Zhu, Yuping Sun, and Hua-Kun Liu
}




\title{
Porous $\mathrm{Ni}_{0.5} \mathrm{Zn}_{0.5} \mathrm{Fe}_{2} \mathrm{O}_{4}$ Nanospheres: Synthesis, Characterization, and Application for Lithium Storage
}

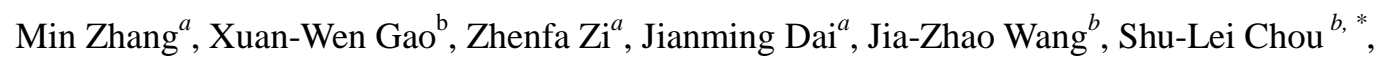

Changhao Liang $^{a}$, Xuebin Zhu ${ }^{a,}{ }^{*}$, Yuping Sun ${ }^{a}$, Hua-Kun Liu ${ }^{b}$

${ }^{a}$ Key Laboratory of Materials Physics, Institute of Solid State Physics, Chinese Academy of Sciences, Hefei 230031, P. R. China.

${ }^{b}$ Institute for Superconducting \& Electronic Materials (ISEM), Innovation Campus, University of Wollongong, Wollongong, NSW 2519, Australia.

*Corresponding author E-mail addresses: shulei@uow.edu.au (S.L. Chou); xbzhu@issp.ac.cn (X.B. Zhu)

\begin{abstract}
Monodisperse porous $\mathrm{Ni}_{0.5} \mathrm{Zn}_{0.5} \mathrm{Fe}_{2} \mathrm{O}_{4}$ nanospheres have been successfully synthesized by the solvothermal method. The diameter of the nanospheres can be tuned by controlling the reactant concentration. Lower reactant concentration is favoured for the synthesis of mesoporous $\mathrm{Ni}_{0.5} \mathrm{Zn}_{0.5} \mathrm{Fe}_{2} \mathrm{O}_{4}$ nanospheres with higher surface area. The electrochemical results show that mesoporous $\mathrm{Ni}_{0.5} \mathrm{Zn}_{0.5} \mathrm{Fe}_{2} \mathrm{O}_{4}$ nanospheres exhibit high reversible specific capacity $\left(1110 \mathrm{mAh} \mathrm{g}^{-1}\right)$ for Li storage and high capacity retention, with $700 \mathrm{mAh} \mathrm{g}^{-1}$ retained up to 50 cycles. The excellent electrochemical properties could be attributed to the large surface area and mesoporous structure. The results suggest that $\mathrm{Ni}_{0.5} \mathrm{Zn}_{0.5} \mathrm{Fe}_{2} \mathrm{O}_{4}$ could be a promising high capacity anode material for lithium ion batteries.
\end{abstract}

Keywords: $\mathrm{Ni}_{0.5} \mathrm{Zn}_{0.5} \mathrm{Fe}_{2} \mathrm{O}_{4}$; nanosphere; porous; anode; Li-ion battery; 


\section{Introduction}

Hollow or porous-structured transition metal oxides are of great interest in many applications, such as catalysts, batteries, supercapacitors, solar cells, and fuel cells [1-7], owing to their large specific surface areas. The Li-ion battery is the most important energy storage device in our daily life for portable devices and potentially for electric vehicles. As possible substitutes for commercial graphite materials (theoretical specific capacity of $372 \mathrm{mAh} \mathrm{g}^{-1}$ ), transition metal oxides have attracted considerable attention from researchers around the world, who are interested in their potential as high capacity anode materials for lithium ion batteries (LIBs) $[8,9]$. Nevertheless, finding electrode materials with high energy density and excellent cycling stability is still a great challenge for LIBs [10-12].

Compared with the various simple transition metal oxides, such as $\mathrm{NiO}, \mathrm{ZnO}$, $\mathrm{Fe}_{2} \mathrm{O}_{3}, \mathrm{Co}_{3} \mathrm{O}_{4}, \mathrm{Cr}_{2} \mathrm{O}_{3}$, and $\mathrm{CuO}$ [7, 13-18], nanostructured spinel ferrites with the general formula $\mathrm{AFe}_{2} \mathrm{O}_{4}(\mathrm{~A}=\mathrm{Ni}, \mathrm{Zn}, \mathrm{Co}, \mathrm{Cu})[6,19-21]$ are of great interest because of their high initial discharge capacity (over $1000 \mathrm{mAh} \mathrm{g}^{-1}$ ). Ding et al. [22] prepared $\mathrm{ZnFe}_{2} \mathrm{O}_{4}$ by the polymer pyrolysis method (PPM), and the ferrite samples prepared via this method show superior capacities and cycling stabilities, with an initial specific capacity as high as $1419.6 \mathrm{mAh} \mathrm{g}^{-1}$ that is maintained at over $800 \mathrm{mAh} \mathrm{g}^{-1}$ even after 50 cycles. Zhao et al. [23] have reported that the initial discharge capacity of nanosized $\mathrm{NiFe}_{2} \mathrm{O}_{4}$ could reach as high as $1314 \mathrm{mAh} \mathrm{g}^{-1}$, which is attributed to the large surface area and short diffusion length of the nanostructure. The discharge capacity, however, decreased to $790.8 \mathrm{mAh} \mathrm{g}^{-1}$ after 2 cycles and to $709.0 \mathrm{mAh} \mathrm{g}^{-1}$ 
after 3 cycles at a current density of $0.2 \mathrm{~mA} \mathrm{~cm}^{-2}$. Liu and co-workers [24] reported that $\mathrm{NiFe}_{2} \mathrm{O}_{4}$ showed the highest reported initial discharge capacity of $1400 \mathrm{mAh} \mathrm{g}^{-1}$, which was due to its nanoscale particle size and better crystallinity, although this material demonstrated relatively poor capacity retention. Zhao's group [25] found that $\mathrm{ZnFe}_{2} \mathrm{O}_{4}$ prepared by the hydrothermal method exhibited the initial discharge capacity of $1287.5 \mathrm{mAh} \mathrm{g}^{-1}$, although the discharge capacity of these nanoparticles declined to $746 \mathrm{mAh} \mathrm{g}^{-1}$ after 2 cycles.

The reaction route, particle size, and morphology of spinel ferrite can play very important roles in the electrochemical performance of LIBs [26, 27]. It was found that the capacity retention of metal oxides can be improved by fabricating materials in hollow or mesoporous nanostructures, which could accommodate volume changes and shorten the lithium diffusion length [15-20]. Hollow $\mathrm{ZnFe}_{2} \mathrm{O}_{4}$ nanospheres with a diameter of $1 \mu \mathrm{m}$ were synthesized by Guo et al. [6] via hydrothermal reaction followed by annealing at $600{ }^{\circ} \mathrm{C}$ in air, and the hollow spherical structure significantly increased the specific capacity and improved capacity retention, although the process required a high reaction temperature, which resulted in agglomeration of the hollow spheres. Deng et al. [28] prepared $\mathrm{ZnFe}_{2} \mathrm{O}_{4}$ hollow spheres of a suitable size with a carbon template. Although the resulting composites showed a high specific capacity of $911 \mathrm{mAh} \mathrm{g}^{-1}$, the synthetic steps are complicated with templates involved. Very recently, Wang et al. [29] successfully synthesized the $\mathrm{MFe}_{2} \mathrm{O}_{4}(\mathrm{M}=\mathrm{Zn}, \mathrm{Co}, \mathrm{Ni})$ nanorods by a template-engaged reaction. The merits of one-dimensional (1D) 
nanostructure and its high reversible capacity make the spine ferrite very prospective candidates as anodes for LIBs.

Cherian et al. [30] studied the effects of zinc-doped nickel ferrite and the consequent cation redistribution on the Li-cycling behavior. An enhancement in the capacity with increasing Zn concentration is observed for $x=0.4$ and 0.6 . In addition, in the case of $\mathrm{Zn}_{1-x} \mathrm{Ni}_{x} \mathrm{Fe}_{2} \mathrm{O}_{4}$ ferrite [31], it was found that for $x$ greater than $0.5, \mathrm{Fe}^{3+}$ moments in A and B sites have a collinear arrangement, whereas for $x$ less than 0.5, $\mathrm{Fe}^{3+}$ moments in the $\mathrm{B}$ sites have a non-collinear arrangement. Therefore, it is necessary to further study the electrochemical properties of $\mathrm{Ni}_{0.5} \mathrm{Zn}_{0.5} \mathrm{Fe}_{2} \mathrm{O}_{4}$ nanospheres.

To avoid the problems mentioned above and obtain high capacity with good capacity retention, we synthesized mesoporous $\mathrm{Ni}_{0.5} \mathrm{Zn}_{0.5} \mathrm{Fe}_{2} \mathrm{O}_{4}$ (NZFO) nanospheres via the solvothermal method and investigated the effects of the morphology on the electrochemical performance. To the best of our knowledge, no group has reported the electrochemical performance of hollow or mesoporous structured NZFO prepared by a one-step solvothermal method. The as-prepared mesoporous NZFO nanospheres showed excellent electrochemical performance with high initial discharge capacity and good capacity retention.

\section{Experimental}

All reagents were analytical grade and were used without further purification. In order to synthesize NZFO, stoichiometric amounts of nickel nitrate, zinc nitrate, and iron nitrate were dissolved in $30 \mathrm{ml}$ ethylene glycol (EG) under magnetic stirring. After stirring for $60 \mathrm{~min}$, a suitable amount of urea was slowly added to the mixed 
nitrate solution. The mixture was stirred for $2 \mathrm{~h}$ to obtain a clear solution. Subsequently, the solution was sealed in a Teflon-lined autoclave (50 ml capacity) and maintained at $180{ }^{\circ} \mathrm{C}$ for $24 \mathrm{~h}$. Then, the mixture was cooled to room temperature naturally. The resultant products were washed with deionized water and ethanol several times, and then dried in a vacuum oven at $80{ }^{\circ} \mathrm{C}$ overnight. For simplicity, the NZFO powders obtained under the same reaction conditions of temperature and reaction time, but with different reactant concentrations, are denoted as NZFO-A, where A represents the mole number of the as-prepared NZFO powders, respectively. For example, NZFO-200 indicates that 0.002 mol NZFO powders were prepared at $180{ }^{\circ} \mathrm{C}$ with $24 \mathrm{~h}$ reaction time. In order to investigate the influence of the reactant concentrations on the final products, the molar ratio of $\mathrm{Ni}\left(\mathrm{NO}_{3}\right)_{2} \cdot 6 \mathrm{H}_{2} \mathrm{O}$, $\mathrm{Zn}\left(\mathrm{NO}_{3}\right)_{2} \bullet 6 \mathrm{H}_{2} \mathrm{O}, \mathrm{Fe}\left(\mathrm{NO}_{3}\right)_{3} \bullet 9 \mathrm{H}_{2} \mathrm{O}$, and urea was kept constant (1:1:4:16), and the volume of EG was fixed at $30 \mathrm{ml}$.

$\mathrm{X}$-ray diffraction (XRD) patterns of the as-prepared products were collected on a Philips X'pert PRO X-ray diffractometer with $\mathrm{Cu} \mathrm{K \alpha}$ radiation. Field emission scanning electron microscopy (FESEM, FEI Sirion 200) and transmission electron microscopy (TEM, JEM-2010) were used to show the surface morphology and particle size distribution. The surface area of the samples was determined by nitrogen adsorption (Autosorb-iQ-Cx).

To test the electrochemical performance, as-prepared samples were mixed with acetylene black (AB) and a binder, sodium carboxymethyl cellulose (CMC, average Mw: 250 000, Aldrich), in a weight ratio of 80:10:10 in deionized water. The slurry 
was uniformly pasted onto pieces of $\mathrm{Cu}$ mesh with an area of $1 \mathrm{~cm}^{2}$. Such prepared electrode sheets were dried at $90{ }^{\circ} \mathrm{C}$ in a vacuum oven for $12 \mathrm{~h}$. The electrodes were not pressed for electrochemical testing. The electrochemical cells (CR 2032 coin-type cells) contained the composite on $\mathrm{Cu}$ mesh as the working electrode, $\mathrm{Li}$ foil as the counter electrode and reference electrode, a porous polypropylene film as separator, and $1 \mathrm{M} \mathrm{LiPF}_{6}$ (battery grade 99.99\%, Aldrich) in a 1:2 (v/v) mixture of ethylene carbonate (EC, anhydrous 99\%, Sigma-Aldrich) and diethyl carbonate (DEC, anhydrous $99+\%$, Sigma-Aldrich) as the electrolyte. The cells were assembled in an Ar-filled glove box. The cells were cycled at a current density of $50 \mathrm{~mA} \mathrm{~g}^{-1}$ between 0.01 and $3.0 \mathrm{~V}$ using a computer-controlled charger system manufactured by Land Battery Testers. The specific capacity is based on the weight of NZFO. The loading mass of NZFO is $3-5 \mathrm{mg} \mathrm{cm}^{-2}$. Electrochemical impedance spectroscopy (EIS) was conducted using a Biologic VMP-3 electrochemical workstation.

\section{Results and discussion}

\subsection{Structure and morphology}

Figure 1 shows the XRD patterns of the Ni-Zn ferrites prepared using different reactant concentrations. All reflection peaks match with the standard JCPDS card of Ni-Zn ferrite (card no. 08-0234), and no other phase is detectable. The lattice constant (a) values, obtained by Rietveld refinement and listed in Table 1, are larger than that of $\mathrm{Fe}_{3} \mathrm{O}_{4}(8.36 \AA)$ [32]. The Rietveld refined XRD pattern of the typical NZFO-300 sample is shown in the inset of Fig. 1. In Fig. 1, the corresponding diffraction peaks become narrower and sharper with increasing concentration, indicating better 
crystalline and growth in crystallite size. The crystallite size $(D)$ was calculated by the Williamson-Hall (W-H) plots equation [33]: $\beta \cos \theta=\varepsilon(4 \sin \theta)+\lambda / D$, where $\beta$ is the measured full width at half maximum (FWHM) for XRD corresponding to different crystal planes, $\theta$ is the Bragg angle, $\varepsilon$ is the strain and $D$ is the crystallite size. The crystallite size increased from 22 to $35 \mathrm{~nm}$ as the reaction concentration increased.

Figure 2 shows the morphology and corresponding size distribution graphs of all the NZFO samples. All the particles show a spherical shape with a rather homogeneous nanosphere size. The size distribution of the nanospheres was estimated by taking the average of 200 nanospheres and fitting the resultant histogram by a Gaussian function (solid line), as shown in the insets of Fig. 2. The average nanosphere sizes are listed in Table 1 . The centre of the size distribution curves was shifted from 145 to $62 \mathrm{~nm}$ as the concentration of the reaction solution was increased from 2 to $4 \mathrm{mM}$, showing the significant influence of the reactant concentration on the nanosphere size. This can be explained by the classical theories of crystal heterogeneous nucleation [34]. In our experiment, the urea can provide centres of heterogeneous nucleation. Therefore, increasing the concentration will lead to a decrease in the average particle size. Open pores and some broken spheres can also be seen in Fig. 2(d), as marked by the arrows, indicating the presence of hollow spheres in the NZFO-300 sample.

Transmission electron microscopy (TEM) was used to further confirm the structure of the nanospheres. Fig. 3 shows TEM images of the NZFO-200, NZFO-300 and 
NZFO-400 samples. Uniform and monodisperse nanospheres are observed. Fig. 3(a), (b), and (c) clearly reveal that the spherical shells are packed with numerous NZFO nanoparticles. In Fig. 3(b), the contrast between the dark edge and the pale center indicates the hollow interior structure of the NZFO-300 nanospheres. High-resolution TEM (HRTEM) analysis was employed to determine the crystal facets and orientation. As shown in Fig. 3(d), (e) and (f), the lattice fringe spacings of $d=0.30 \mathrm{~nm}$ and $d=$ $0.25 \mathrm{~nm}$ agree well with the (220) and (311) lattice planes of the XRD patterns of cubic NZFO, respectively. The different contrast in Fig. 3(d) and (e) indicates that NZFO-200 and NZFO-300 may have a porous structure with pore size smaller than 5 $\mathrm{nm}$.

Fig. 4 presents the $\mathrm{N}_{2}$ adsorption-desorption isotherms of the samples and the corresponding Barret-Joyner-Halenda $(\mathrm{BJH})$ pore size distribution curves. The measured Brunauer-Emmett-Teller (BET) surface area $\left(S_{\mathrm{BET}}\right)$ for NZFO-200 and NZFO-300 is about 101.3 and $77.2 \mathrm{~m}^{2} \mathrm{~g}^{-1}$, respectively. It can be seen that the $S_{\mathrm{BET}}$ decreases from 101.3 to $77.2 \mathrm{~m}^{2} \mathrm{~g}^{-1}$ as the reaction concentration increases. The relatively high $S_{\mathrm{BET}}$ for NZFO-200 may be due to its narrow particle size distribution, as shown in Fig. 4(c). The isotherms in Fig. 4(a) and (b) are identified as type IV, which is characteristic of mesoporous $(2-50 \mathrm{~nm})$ materials [35]. The NZFO-200 sample has sharp peaks at 2 and $31 \mathrm{~nm}$, indicating the presence of mesopores.

The formation of the hollow NZFO nanospheres could be explained by the Ostwald ripening process [28]. In the sealed solvothermal reaction system, $\mathrm{CO}_{2}$ bubbles resulting from the thermal decomposition of urea can serve as soft templates to induce 
the hollow/porous nanostructure. The gas bubbles provide the nucleation centers for NZFO nanoparticles to aggregate around the gas-liquid interface. As the reaction proceeds, hollow NZFO nanospheres are formed.

Fig. 5 contains a schematic illustration of the formation mechanism of the hollow/mesoporous nanospheres. Based on the above analysis, when the reactant concentration is relatively low, the size of the bubbles generated from the decomposition of urea is too small to accelerate the Ostwald ripening because the gas is trapped between the interfaces, resulting in mesoporous spheres. Therefore, the urea only has a positive effect on the reduction capability of ethylene glycol, but there is not enough gas for the bubbles to act as soft templates, so that porous-structured nanospheres are only partially formed. As the reactant concentration increases, more gas bubbles are produced, thus accelerating the Ostwald ripening process, which results in the formation of hollow nanospheres. According to the formation of crystals [36], the rate of the generation or the quantity of the gas bubbles plays an important role in controlling the particle size. In the same volume of the EG, as urea increases to a higher amount, the more bubbles are produced, and the quantity of $\mathrm{Ni}_{0.5} \mathrm{Zn}_{0.5} \mathrm{Fe}_{2} \mathrm{O}_{4}$ aggregation in each bubble will be reduced, resulting in the decrease of the nanosphere size.

\subsection{Electrochemical characterizations}

Figure 6 shows the charge-discharge curves of selected cycles for the first 50 cycles of NZFO-200, NZFO-300, and NZFO-400 electrodes in coin test cells using lithium as the counter and reference electrode between 0.01 and $3.0 \mathrm{~V}$ (vs. 
$\left.\mathrm{Li}^{+} / \mathrm{Li}\right)$. All the charge-discharge curves in Fig. 6 show similar features to those of transition metal oxide electrodes reported previously in the literature [15, 23-25]. The first discharge curves all show a plateau at $0.75 \mathrm{~V}$. The initial discharge specific capacity is in the order of NZFO-200 > NZFO-300 > NZFO-400.

The theoretical capacity of NZFO from the reduction reactions of Ni (II), Zn (II), and Fe (III) to Ni (0), Zn (0), and Fe (0), respectively, is $902 \mathrm{mAh} \mathrm{g}^{-1}$, corresponding to a maximum lithium uptake of $8 \mathrm{Li}$ per NZFO. The equation is as follows:

$$
2 \mathrm{Ni}_{0.5} \mathrm{Zn}_{0.5} \mathrm{Fe}_{2} \mathrm{O}_{4}+16 \mathrm{Li}^{+}+16 \mathrm{e}^{-} \rightarrow 4 \mathrm{Fe}+\mathrm{Zn}+\mathrm{Ni}+16 \mathrm{Li}_{2} \mathrm{O}
$$

The initial discharge capacity is always higher than the theoretical capacity, which is due to the decomposition of electrolyte and the formation of the solid electrolyte interphase (SEI). The possible reaction between $\mathrm{Zn}$ and $\mathrm{Li}$ would be another contribution to the high capacity [37].

$$
\mathrm{Zn}+\mathrm{Li}^{+}+\mathrm{e} \leftrightarrow \mathrm{LiZn}
$$

The highest surface area sample, NZFO-200, shows the highest initial discharge capacity of $1480 \mathrm{mAh} \mathrm{g}^{-1}$. The reversible capacity is due to the reversible reaction of $\mathrm{Li}_{2} \mathrm{O}$ and the transition metals:

$$
4 \mathrm{Fe}+\mathrm{Zn}+\mathrm{Ni}+8 \mathrm{Li}_{2} \mathrm{O} \leftrightarrow \quad 2 \mathrm{Fe}_{2} \mathrm{O}_{3}+\mathrm{ZnO}+\mathrm{NiO}+16 \mathrm{Li}^{+}+16 \mathrm{e}^{-}
$$


The highest reversible capacities were also observed for the NZFO-200 sample, up to $1100 \mathrm{mAh} \mathrm{g}^{-1}$.

The $d Q / d V$ results are also plotted in Fig. 7. In the $1^{\text {st }}$ cycle [Fig. 7(a)], an additional peak can be found at 0.46 and $0.66 \mathrm{~V}$ for the NZFO-200 and NZFO-300 samples, respectively. This may be due to the further lithiation of $\mathrm{ZnO}$ to give a $\mathrm{Li}-\mathrm{Zn}$ alloy, as a similar peak between 0.2 and $0.5 \mathrm{~V}$ was observed in the literature [38]. The high intensity of the $0.46 \mathrm{~V}$ peak of the NZFO-200 sample indicates the highly reversible reaction of $\mathrm{Zn}$ and lithium, which can be attributed to the mesoporous structure with small crystallite size and high surface area. Fig. 7(b) presents the $d Q / d V$ curves of the $50^{\text {th }}$ cycle. One pair of redox peaks can be found at $1.0 \mathrm{~V}$ and $1.6 \mathrm{~V}$ for the NZFO-200 and NZFO-300 samples. The higher intensity of NZFO-200 indicates higher capacity. The NZFO-400 sample shows small reversible peaks, indicating the lowest reversible capacity.

The cycle life is shown in Fig. 8. The capacity retention is in the same order as the surface area. The best capacity retention that can be obtained here is for the NZFO-200 sample with $700 \mathrm{mAh} \mathrm{g}^{-1}$ up to 50 cycles. Our results show that the performance of the mesoporous nanosphere electrode (NZFO-200) with high surface area is better than that of the hollow/porous nanosphere electrode (NZFO-300) with low surface area in terms of reversible capacity and cycle life. It is also worth mentioning that there is a large deviation in potential between the charge and discharge profiles, owing to the large polarization related to ion 
transfer during the cycling process. This phenomenon is often observed in many metal oxide anodes due to poor electrical conductivity [15,16,39,40].

The rate performance was also investigated to characterize the stability of the NZFO-200 and NZFO-400 electrodes, as shown in Fig. 9. The NZFO-200 electrode shows the highest specific capacity of $508 \mathrm{mAh} \mathrm{g}^{-1}$ at a current density of $1 \mathrm{~A} \mathrm{~g}^{-1}$. The capacity retention rates at $500 \mathrm{~mA} \mathrm{~g}^{-1}$ and $1 \mathrm{~A} \mathrm{~g}^{-1}$ are $75.5 \%$ and $56.1 \%$ compared to the $100 \mathrm{~mA} \mathrm{~g}^{-1}$ capacity, respectively. In comparison, the NZFO-400 electrode shows relatively poor high rate capability, with less than $15 \%$ capacity retention at current density of $1 \mathrm{~A} \mathrm{~g} \mathrm{~g}^{-1}$. The high rate capability can be attributed to the high surface area and mesoporous structure, which can enhance contact between the electrode and electrolyte, and shorten the lithium diffusion length.

To investigate the reasons for the enhanced capacity retention in NZFO-200, the electrodes were washed and dried after cycling, and the changes in morphology were examined by SEM. SEM images of the surfaces of the electrodes before and after cycling are shown in Fig. 10. The top SEM images show the electrode surfaces before cycling, while the bottom ones show the surfaces after 50 cycles. The electrodes before cycling show a similar smooth surface, while after cycling, the electrode morphology shows big differences. The surface of the NZFO-200 electrode after cycling shows a porous morphology, while the NZFO-400 electrode shows morphology that features big cracks. The growth of the big cracks will produce high resistance and cause contact between the active materials to be lost, resulting in poor capacity retention. The difference in the electrode morphology could be related to the differences in the morphology and surface area of the active materials. Since the formation of the solid electrolyte interphase (SEI) layer plays a very important role in the cycling stability of the active materials, the higher surface area and mesoporous 
structure of NZFO-200 could be of benefit for the formation of more stable SEI compared with NZFO-400.

Electrochemical impedance spectroscopy (EIS) was used to explain the reasons for the enhanced rate capability and capacity retention of the NZFO-200 electrode. The Nyquist plots (Figure 11) show a semicircle in the high to medium frequency range, which describes the charge-transfer resistance $\left(R_{\mathrm{ct}}\right)$ for both electrodes. The intercept value is considered to represent the total electrical resistance offered by the electrolyte $\left(R_{\mathrm{s}}\right)$. The inclined line represents the Warburg impedance $\left(Z_{\mathrm{w}}\right)$ at low frequency, which indicates the diffusion of $\mathrm{Li}^{+}$in the solid matrix. The impedance plots were fitted using the equivalent circuit model shown in the inset. The $R_{\mathrm{ct}}$ of the NZFO-200 after 5 cycles $(140 \Omega)$ and after 50 cycles $(254 \Omega)$ is much smaller than those of the NZFO-400 after 5 cycles (188 $\Omega$ ) and after 5 cycles (560 $\Omega$ ), respectively, giving evidence that the high surface area of the NZFO-200 improved the battery performance over extended cycling. However, the capacity still gradually decreases for all samples. Further work can be done to improve the capacity retention via making carbon composite materials.

\section{Conclusions}

In summary, monodisperse mesoporous $\mathrm{Ni}_{0.5} \mathrm{Zn}_{0.5} \mathrm{Fe}_{2} \mathrm{O}_{4}$ nanospheres have been synthesized via a one-step solvothermal method. Nanospheres with different morphologies, crystallite sizes, and diameters can be tuned by adjusting the reactant concentration, which has been confirmed by the XRD, FESEM, and TEM observations. The formation mechanisms of the mesoporous 
and/or hollow nanospheres have been discussed based on the Ostwald ripening process. The mesoporous $\mathrm{Ni}_{0.5} \mathrm{Zn}_{0.5} \mathrm{Fe}_{2} \mathrm{O}_{4}$ nanospheres with small crystallite size and high surface area show high reversible specific capacity and better capacity retention, suggesting that mesoporous $\mathrm{Ni}_{0.5} \mathrm{Zn}_{0.5} \mathrm{Fe}_{2} \mathrm{O}_{4}$ nanospheres can have promising applications in lithium ion batteries.

\section{Acknowledgements}

This work was supported by the National Basic Research Program of China (2014CB931704), the Natural Science Foundation of China (NSFC 11274314), and the Australian Research Council (Discovery Project, DP110103909). The authors would like to also thank Dr Tania Silver for critical reading of the manuscript.

\section{References}

[1] Y.S. Hu, Y.G. Guo, W. Sigle, S. Hore, P. Balaya, J. Maier, Nat. Mater. 5 (2006) 713-717.

[2] M.H. Oh, T. Yu, S.H. Yu, B. Lim, K.T. Ko, M.G. Willinger, D.H. Seo, B.H. Kim, M.G. Cho, J.H. Park, K. Kang, Y.E. Sung, N. Pinna, T. Hyeon, Science 340 (2013) 964-968.

[3] T. Brezesinski, J. Wang, S.H. Tolbert, B. Dunn, Nat. Mater. 9 (2010) 146-151.

[4] T. Suzuki, Z. Hasan, Y. Funahashi, T. Yamaguchi, Y. Fujishiro, M. Awano, Science 325 (2009) 852-855.

[5] E.J.W. Crossland, N. Noel, V. Sivaram, T. Leijtens, J.A. Alexander-Webber, H.J. Snaith, Nature 495 (2013) 215-219. 
[6] X.W. Guo, X. Lu, X.P. Fang, Y. Mao, Z.X. Wang, L.Q. Chen, X.X. Xu, H. Yang, Y.N. Liu, Electrochem. Commun. 12 (2010) 847-850.

[7] X.H. Wang, L. Qiao, X.L. Sun, X.W. Li, D.K. Hu, Q. Zhang, D.Y. He, J. Mater. Chem. A 1 (2013) 4173-4176.

[8] a) P. Poizot, S. Laruelle, S. Grugeon, L. Dupont, J.M. Tarascon, Nature 407 (2000) 496-499; b) J. Chen, F.Y. Cheng, Acc. Chem. Res. 42 (2009) 713-723; c) J. Cabana, L. Monconduit, D. Larcher, M.R. Palacin, Adv. Mater. 22 (2010) E170-E192.

[9] X. Gu, L. Chen, S. Liu, H.Y. Xu, J. Yang, Y.T. Qian, J. Mater. Chem. A 2 (2014) 3439-3444.

[10] J.M. Tarascon, M. Armand, Nature 414 (2001) 359-367.

[11] H. Li, Z.X. Wang, L.Q. Chen, X.J. Huang, Adv. Mater. 21 (2009) 4593-4607.

[12] X. Fang, M.Y. Ge, J.P. Rong, C.W. Zhou, J. Mater. Chem. A 1 (2013) 4083-4088.

[13] M.M. Titirici, M. Antonietti, A. Thomas, Chem. Mater. 18 (2006) 3808-3812.

[14] H.B. Wang, Q.M. Pan, Y.X. Cheng, J.W. Zhao, G.P. Yin, Electrochim. Acta 54 (2009) 2851-2855.

[15] S.L. Chou, J.Z. Wang, D. Wexler, K. Konstantinov, C. Zhong, H.K. Liu, S.X. Dou, J. Mater. Chem. 20 (2010) 2092-2098.

[16] a) H. Liu, X.W. Du, X.R. Xing, G.X. Wang, S.Z. Qiao, Chem. Commun. 48 (2012) 865-867; b) H. Liu, G.X. Wang, J. Liu, S.Z. Qiao, H.J. Ahn, J. Mater. Chem. 21 (2011) 3046-3052.

[17] J. Hu, H. Li, X.J. Huang, L.Q. Chen, Solid State Ionics 177 (2006) 2791-2799. 
[18] B. Wang, X.L. Wu, C.Y. Shu, Y.G. Guo, C.R. Wang, J. Mater. Chem. 20 (2010) 10661-10664.

[19] P. Lavela, J.L. Tirado, J. Power Sources 172 (2007) 379-387.

[20] a) J. Haetge, C. Suchomski, T. Brezesinski, Inorg. Chem. 49 (2010) 11619-11626; b) L.L. Li, Y. Cheah, Y.W. Ko, P. Teh, G. Wee, C.L. Wong, S.J. Peng, M. Srinivasan, J. Mater. Chem. A 1 (2013) 10935-10941.

[21] a)Y. Ding, Y.F. Yang, H.X. Shao, Solid State Ionics 217 (2012) 27-33; b) Z. Xing, Z.C. Ju, J. Yang, H.Y. Xu, Y.T. Qian, Electrochim. Acta 102 (2013) 51-57.

[22] Y. Ding, Y.F. Yang, H.X. Shao, Electrochim. Acta 56 (2011) 9433-9438.

[23] H.X. Zhao, Z. Zheng, K.W. Wong, S.M. Wang, B.J. Huang, D. Li, Electrochem. Commun. 9 (2007) 2606-2610.

[24] H.W. Liu, H. Zhu, H.M. Yang, Mater. Res. Bull. 48 (2013) 1587-1592.

[25] H.X. Zhao, H.M. Jia, S.M.Wang, D.Q. Xue, Z. Zheng, J. Exp. Nanosci. 6 (2011) 75-83.

[26] J. Su, M. H.W. Cao, L. Ren, C. Hu, J. Mater. Chem. C 115 (2011) 14469-14477.

[27] C.C. Ai, M.C. Yin, C.W. Wang, J.T. Sun, J. Mater. Sci. 39 (2004) 1077-1079.

[28] Y.F. Deng, Q.M. Zhang, S.D. Tang, L.T. Zhang, S.N. Deng, Z.C. Shi, G.H. Chen, Chem. Commun. 47 (2011) 6828-6830.

[29] N.N. Wang, H.Y. Xu, L. Chen, X. Gu, J. Yang, Y.T. Qian, J. Power Sources 247 (2014) 163-169.

[30] C.T. Cherian, M.V. Reddy, G.V.S. Rao, C.H. Sow, B.V.R. Chowdari, J. Solid State Electrochem. 16 (2012) 1823-1832. 
[31] N. Ponpandian, A. Narayanasamy, C. N. Chinnasamy, N. Sivakumar, J.M. Greneche, Appl. Phys. Lett. 86 (2005) 1-3.

[32] X. Li, G.S. Wang, J. Magn. Magn. Mater. 321 (2009) 1276-1279.

[33] S. Zhou, X.D. Fang, Z.H. Deng, D. Li, W.W. Dong, R.H. Tao, G. Meng, T. Wang, X.B. Zhu, J. Crystal Growth 310 (2008) 5375-5379.

[34] W.Q. Jiang, Z. Cao, R. Gu, X.Z. Ye, C.F. Jiang, X.L. Gong, Smart Mater. Struct. 18 (2009) 125013.

[35] Y.X. Zhang, G.H. Li, Y.C. Wu, Y.Y. Luo, L.D. Zhang, J. Mater. Chem. B 109 (2005) $5478-5481$.

[36] X.H. Lin, G.B. Ji, Y.S. Liu, Q.H. Huang, Z.H. Yang, Y.W. Dou, CrystEngcomm 14 (2012) 8658-8663.

[37] J.Q. Wang, P. King, R.A. Huggins, Solid State Ionics 20 (1986) 185-189.

[38] Y. Sharma, N. Sharma, G.V. Subba Rao, B.V.R. Chowdari, Adv. Funct. Mater. 17 (2007) 2855-2861.

[39] X. B. Zhu, S.L. Chou, L. Wang, Q. Li, D. Q. Shi, J.Z. Wang, Z.X. Chen, Y.P. Sun, H. K. Liu, S.X. Dou, Electrochem. Solid-State Lett. 12 (2009) A176 - A180.

[40] L. Li, S.J. Peng, Y. Cheah, Y. Ko, P. Teh, G. Wee, C. Wong, M. Srinivasan, Chem. - A Euro. J. 19 (2013) 14823-14830. 


\section{Table caption}

Table 1 Lattice constant $a(\AA)$, crystallite size (nm), and nanosphere size (nm) of the NZFO samples as a function of the reactant concentration.

\begin{tabular}{cccc}
\hline \hline sample & Lattice constant & Crystallite size & Nanosphere size \\
$(\AA)$ & $(\mathrm{nm})$ & $(\mathrm{nm})$ \\
\hline NZFO-200 & 8.3796 & 22 & 145 \\
NZFO-300 & 8.3811 & 23 & 125 \\
NZFO-400 & 8.3865 & 35 & 62 \\
\hline \hline
\end{tabular}




\section{Figure captions}

Fig. 1 XRD patterns of NZFO sampleswith different reactant concentrations; the inset shows the Rietveld refinement results for NZFO-300.

Fig. 2 FESEM images of NZFO ferrite produced with different reactant concentrations, with the insets showing the corresponding particle size distribution graphs: (a) NZFO-200, (b) NZFO-300, (c) NZFO-400; and (d) a high-magnification FESEM image of NZFO-300. The arrows in (d) indicate broken nanospheres, showing their hollow nature.

Fig. 3 TEM images of NZFO ferrite synthesized with different reactant concentrations: (a) NZFO-200, (b) NZFO-300, (c) NZFO-400; high magnification TEM images: (d) NZFO-200, (e) NZFO-300, (f) NZFO-400.

Fig. 4 Nitrogen adsorption-desorption isotherms of (a) NZFO-200, (b)NZFO-300; and pore size distributions of (c) NZFO-200, (d) NZFO-300 (insets: magnified 0-5 nm regions).

Fig. 5 Schematic illustration of the formation mechanism of hollow magnetic nanospheres. 
Fig. 6 Charge and discharge curves for selected cycles of NZFO-200 (a), NZFO-300 (b), and NZFO-400 (c) electrodes.

Fig. $7 d Q / d V$ curves of NZFO-200, NZFO-300, and NZFO-400 electrodes at the $1^{\text {st }}$ cycle (a) and the $50^{\text {th }}$ cycle (b).

Fig. 8 Cycle life of NZFO-200 (red), NZFO-300 (green), and NZFO-400(blue) electrodes.

Fig. 9 Rate performance of NZFO-200 and NZFO-400 electrodes at different current density rates from $100 \mathrm{~mA} \mathrm{~g}^{-1}$ to $1000 \mathrm{~mA} \mathrm{~g}^{-1}$ and back to 100 $\mathrm{mA} \mathrm{g}^{-1}$ between 0.01 and $3.0 \mathrm{~V}$.

Fig.10 SEM images of the electrode surface of NZFO-200 electrode (a, b) and NZFO-400 electrode (c, d), before (a, c) and after (b, d) 50 cycles.

Fig. 11 Nyquist plots of NZFO-200 electrode and NZFO-400 electrode, after cycling over 5 and 50 cycles at a discharge potential of $0.7 \mathrm{~V} \mathrm{vs.} \mathrm{Li}^{\prime} \mathrm{Li}^{+}$at $25{ }^{\circ} \mathrm{C}$ at frequencies from $100 \mathrm{kHz}$ to $20 \mathrm{mHz}$. The inset is the equivalent circuit used. 
Figure 1, Zhang et al.

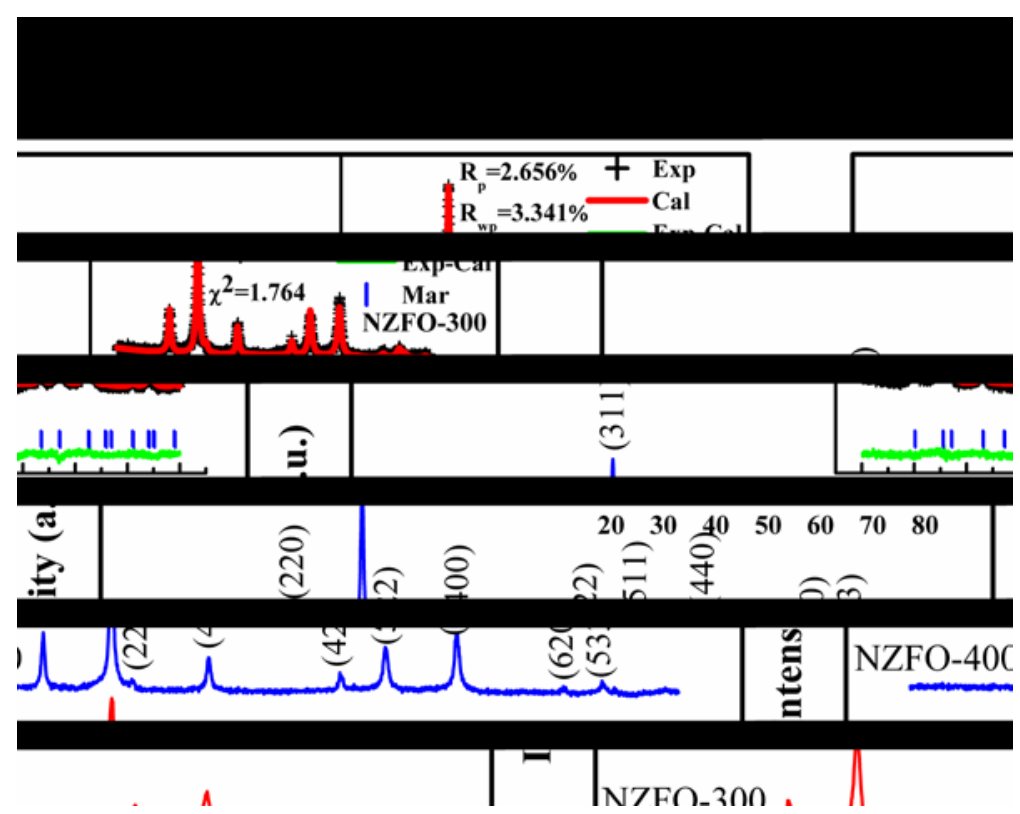


Figure 2, Zhang et al.

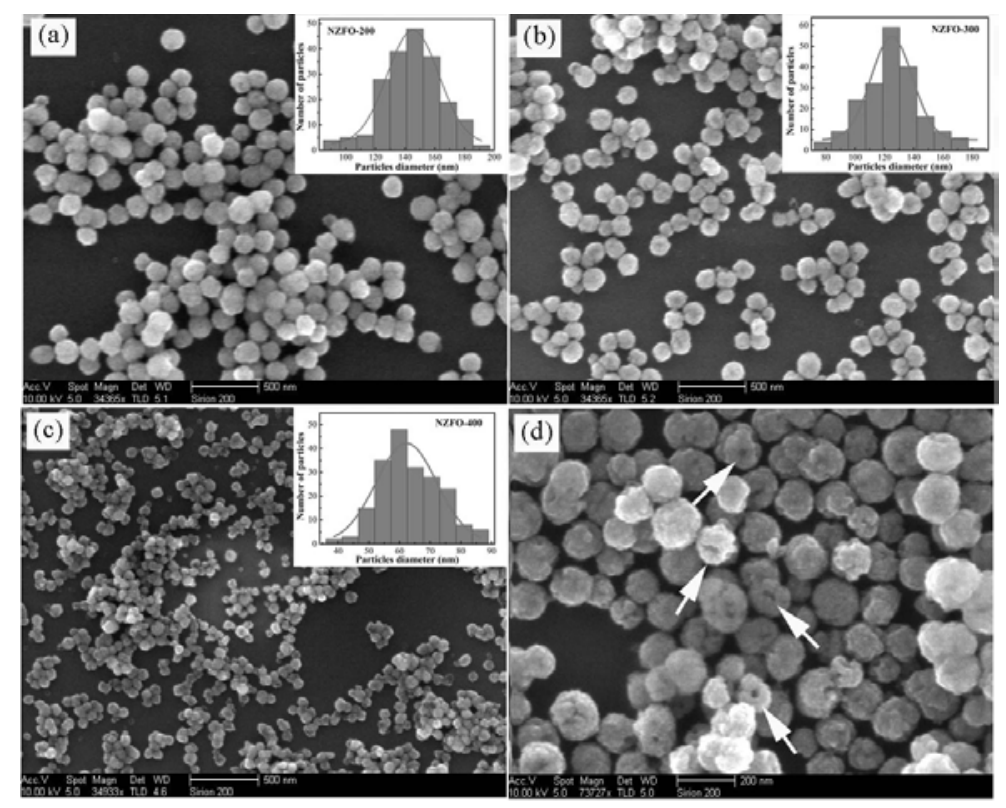


Figure 3, Zhang et al.

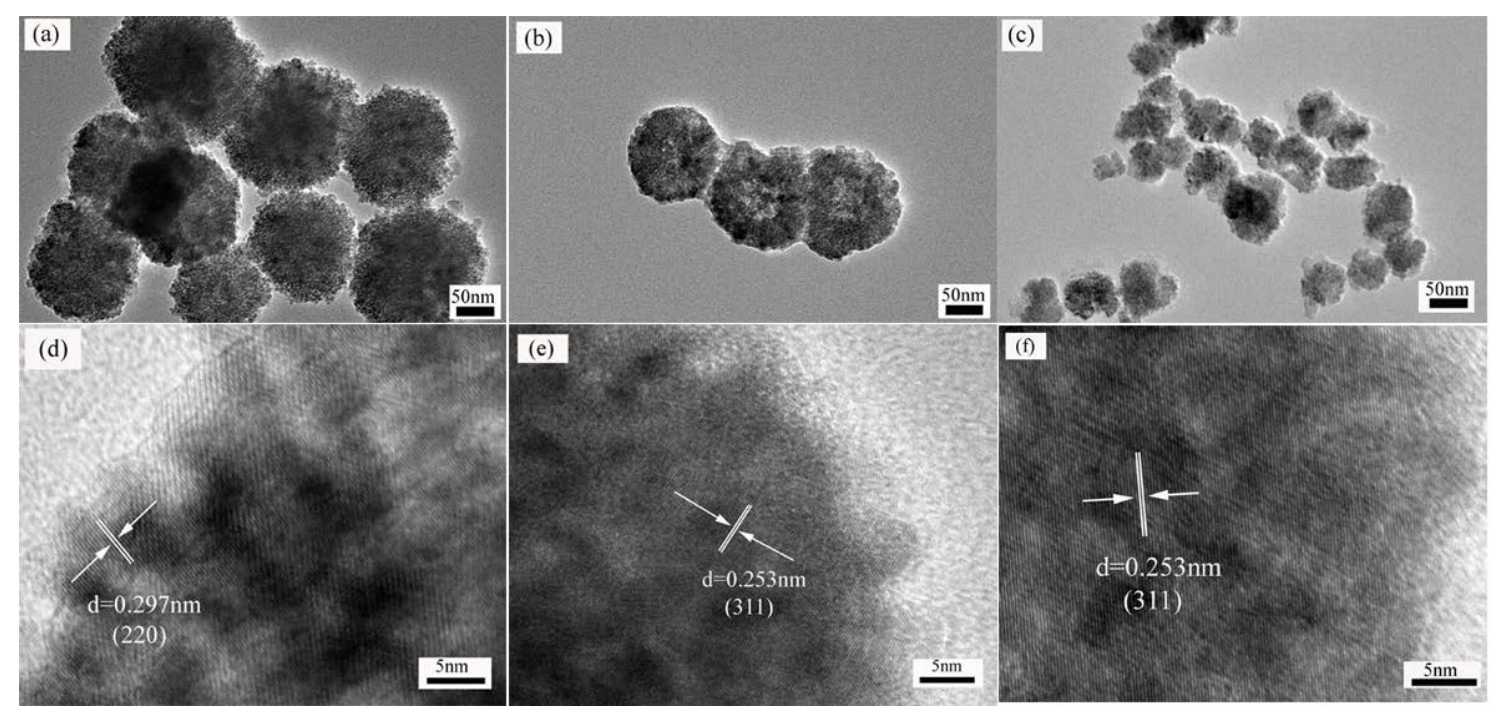


Figure 4, Zhang et al.
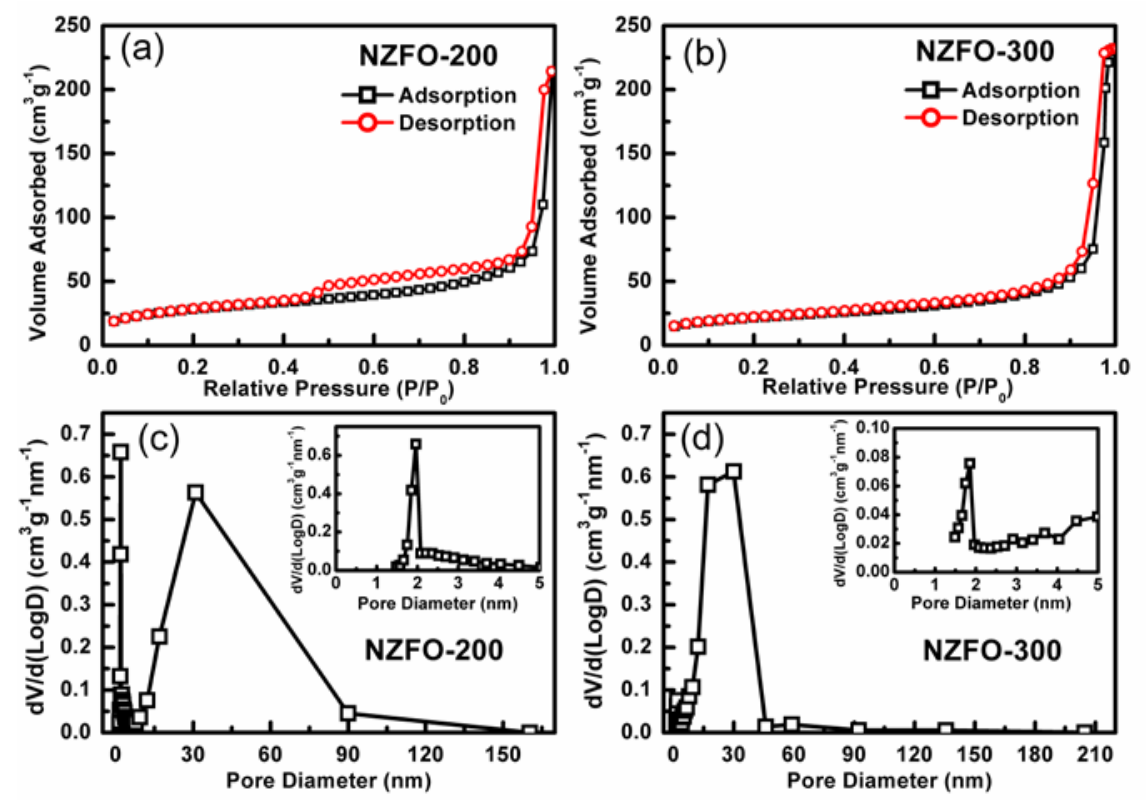
Figure 5, Zhang et al.

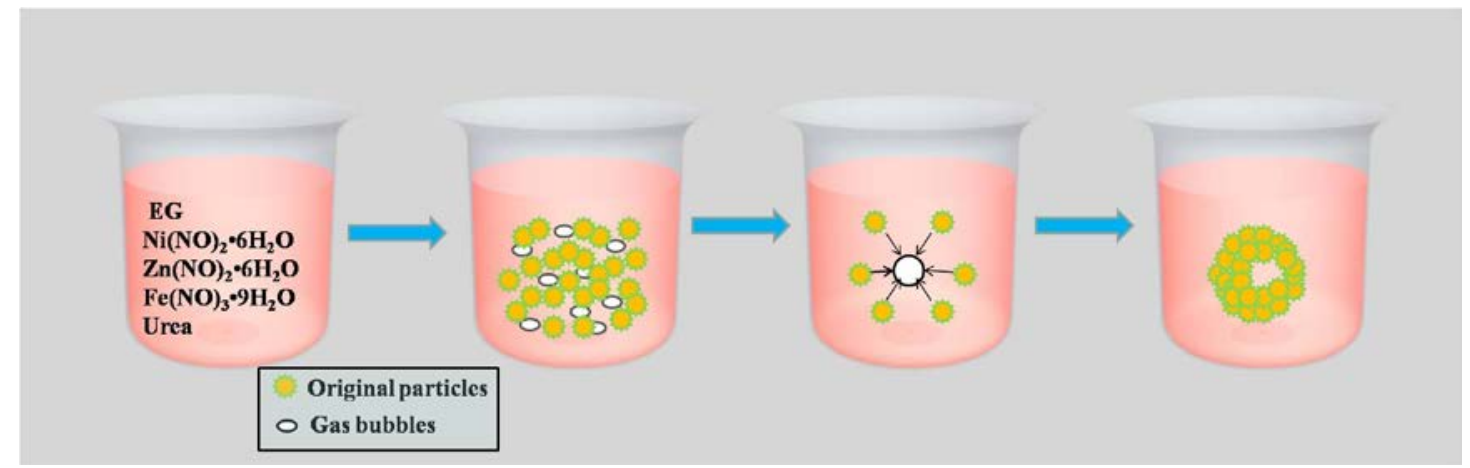


Figure 6, Zhang et al.
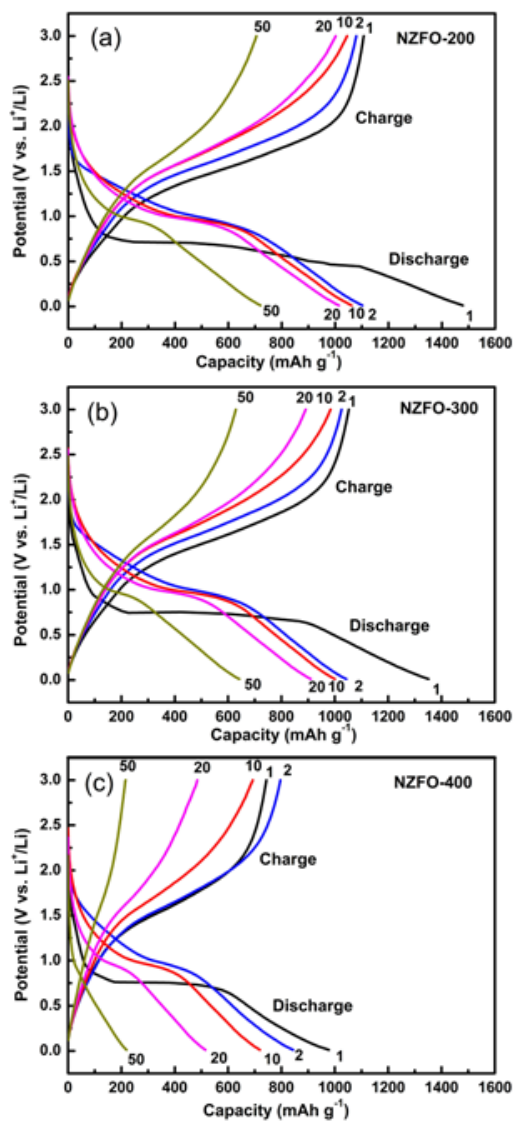
Figure 7, Zhang et al.
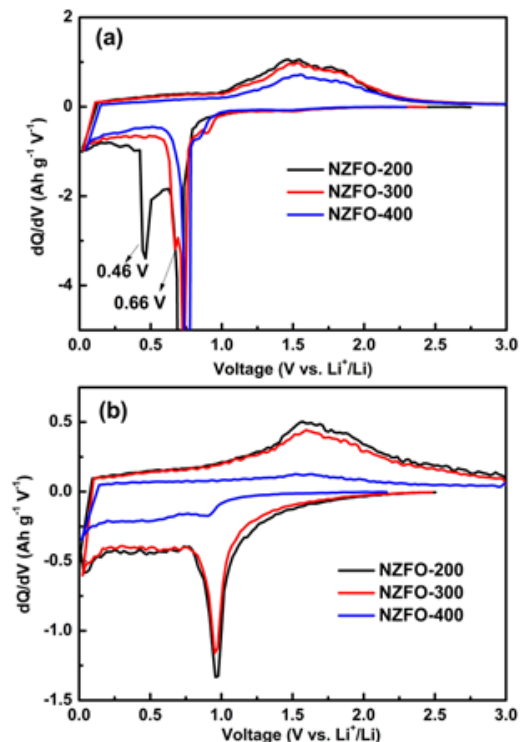
Figure 8, Zhang et al.

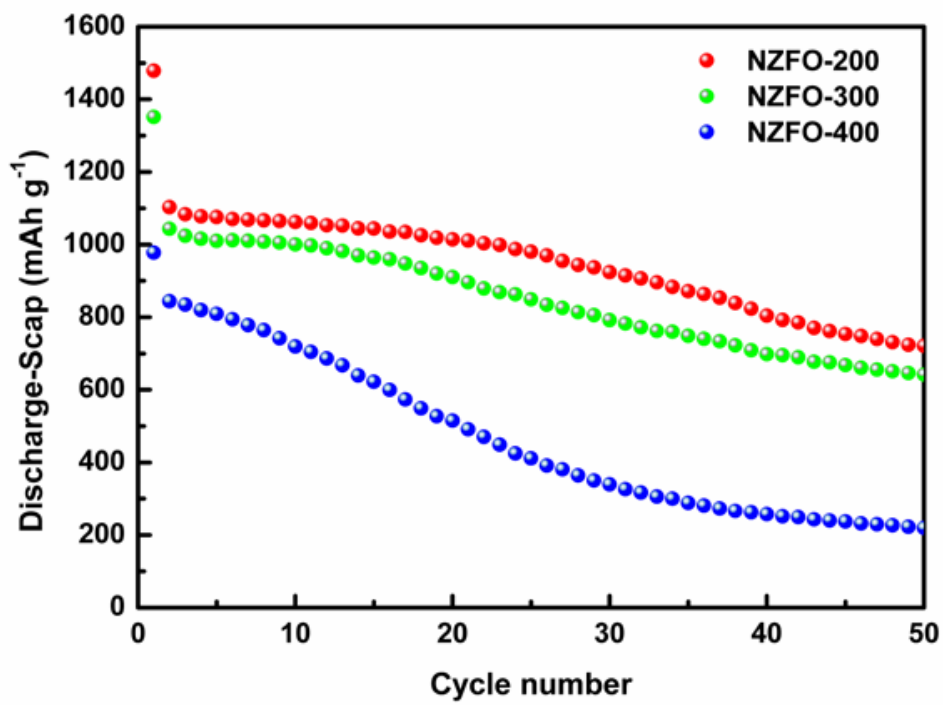


Figure 9, Zhang et al.

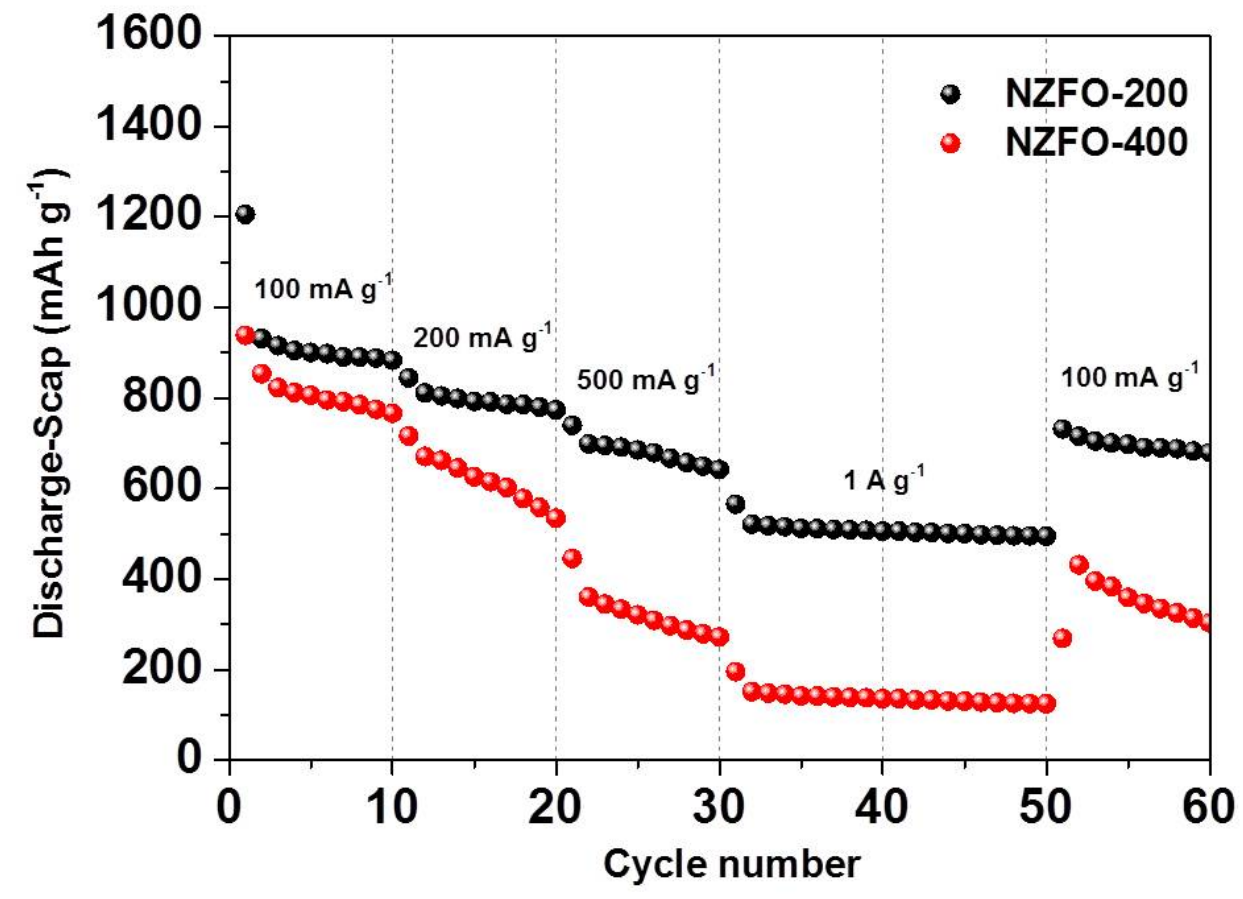


Figure 10, Zhang et al.
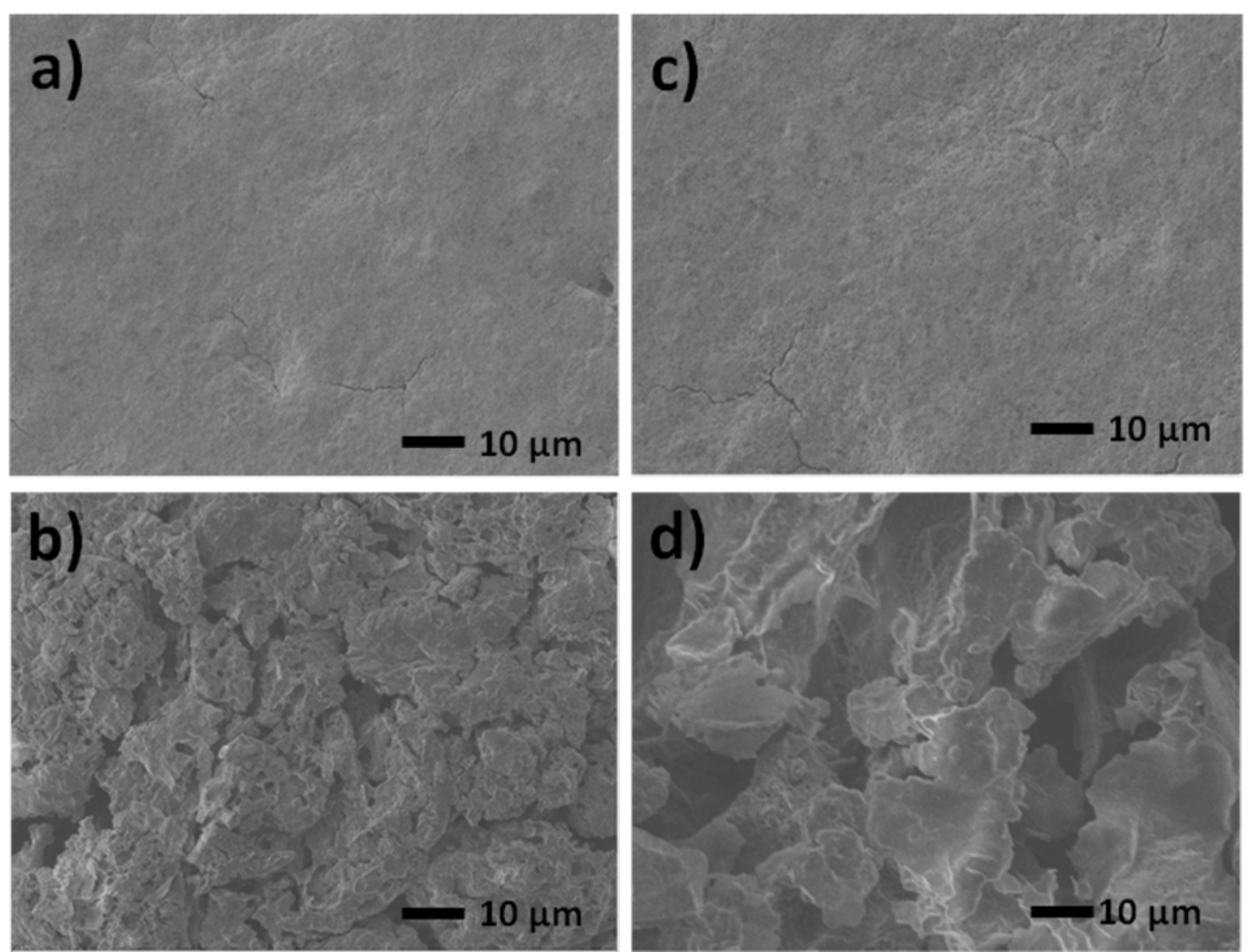
Figure 11, Zhang et al.

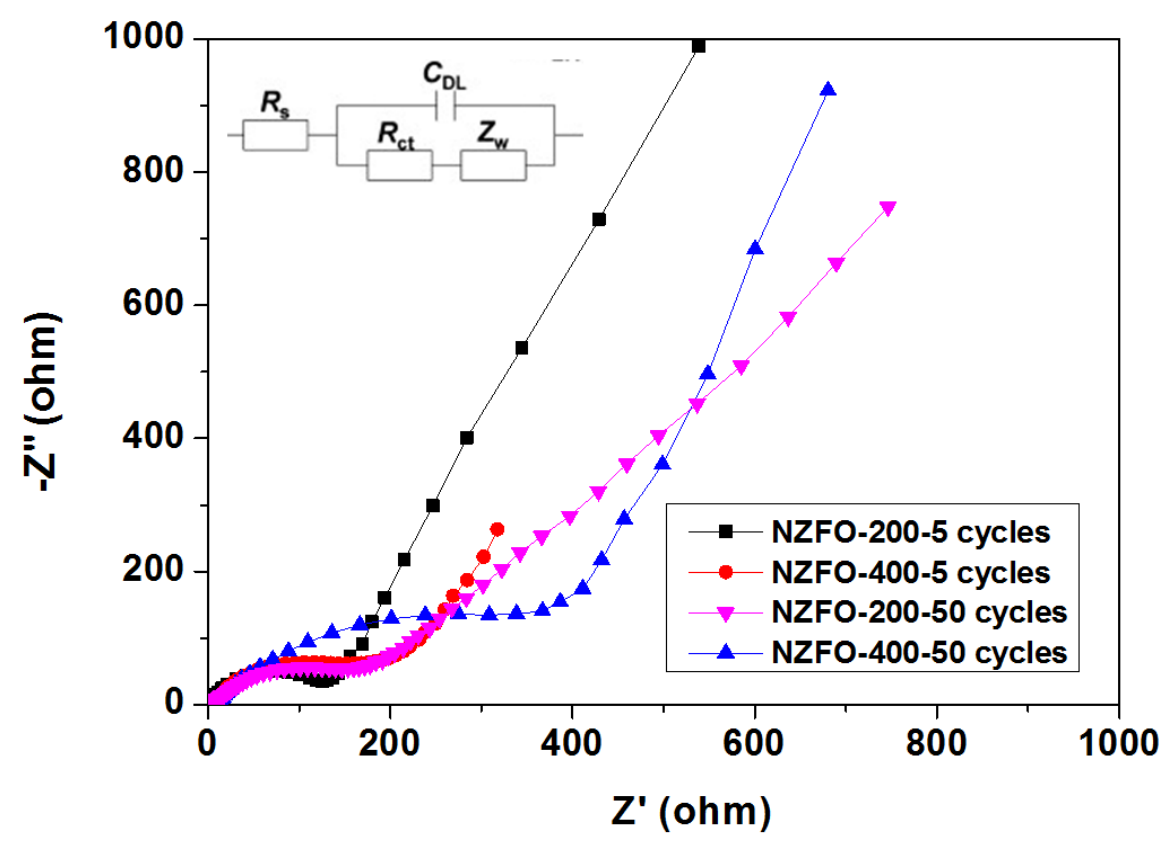

